\title{
Design of shape and dimensions of exchangeable jaws for pneumatics chuck of CNC lathe EMCO Concept TURN 105
}

\author{
Marcela Bučányová ${ }^{1, *}$, Erika Hrušková ${ }^{1}$, and Martina Kusá ${ }^{1}$ \\ ${ }^{1}$ Slovak University of Technology, Faculty of Materials Science and Technology in Trnava, Jána \\ Bottu 2781/25, 91724 Trnava, Slovak Republic
}

\begin{abstract}
The EMCO Concept Turn $105 \mathrm{CNC}$ lathe is part of the iCIM3000 production system. Currently, only a narrow range of products is processed, which is caused by the small clamping range of the 3 -jaw pneumatic chuck marked KFD 85/3. Based on the requirement to expand or change the range of manufactured components, new interchangeable jaws will be designed to clamp more diameters despite a small clamping range. The design of the replaceable jaws for the pneumatic chuck is based on the determination of the shapes and dimensions of the components produced on the lathe, as well as on the shape, dimensions and characteristics of the pneumatic chuck.
\end{abstract}

\section{Present assortment of products and shape of exchangeable jaws}

It is desirable to extend or change the assortment of manufactured components and to design new replaceable jaws. The design of the replaceable jaws for the pneumatic chuck itself is based on the determination of the shapes, dimensions and material of the components produced on the asked lathe as well as the shape, dimensions and properties of the pneumatic chuck.
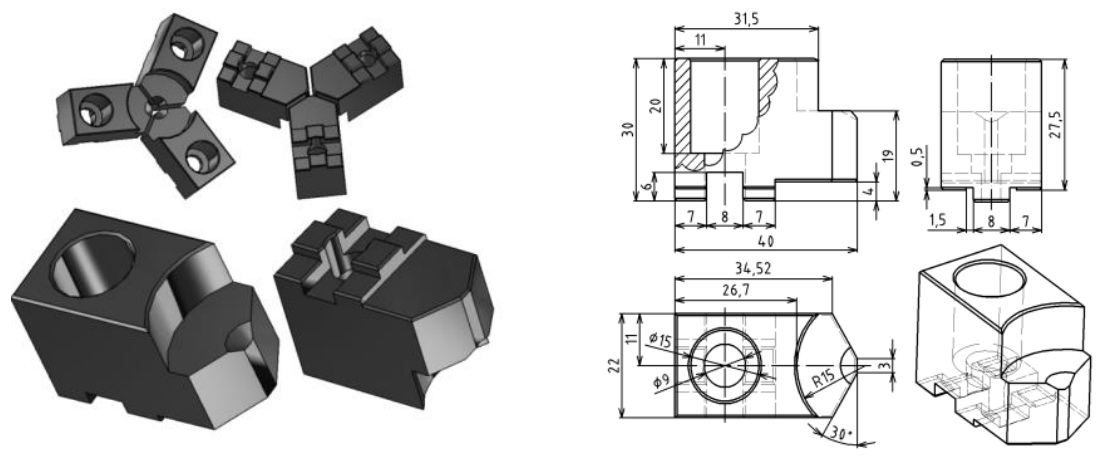

Fig. 1. Model and base dimension of present jaws

\footnotetext{
*Corresponding author: marcela.bucanyova@stuba.sk, martina.kusa@stuba.sk
} 
The EMCO Concept Turn 105 CNC Lathe is currently machining a narrow range of products due to the small clamping range of the 3 -jawed pneumatic chuck KFD 85/3. Clamping range is $3 \mathrm{~mm}$.

The jaws on the lathe chuck are limited in their shape and dimensions to machining single-piece blanks. In Fig. 1 is a model and an overview of the basic dimensions of the present jaws.

Semi-finished products to be machined are aluminium based alloys and brass bars with a diameter of $30 \mathrm{~mm}$. Semi-manufactured parts are made the products that create component base. The base station thus consists of seven components produced in two variants, the first variant being seven components made of aluminium based alloys and the other one being components made of brass, Fig. 2.
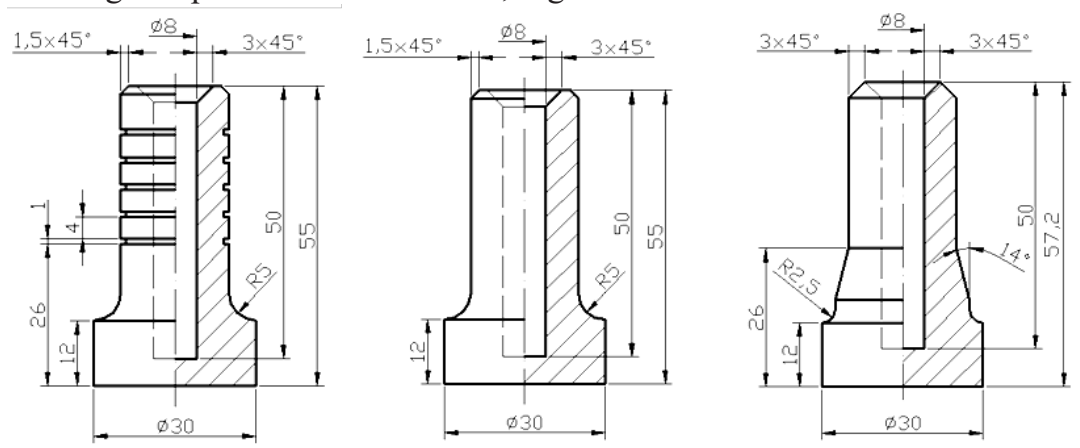

Fig. 2. Present part base

\section{Determination of design conditions}

It is required to clamp two different tool diameters into replaceable jaws. The design of the replaceable jaws for the pneumatic chuck on the EMCO Concept Turn 105 CNC lathe consists of the following design conditions.

\subsection{Shape and dimensions of manufactured components on the lathe}

The new component base is shown in Fig. 3. New jaws designed to bend both parts will be designed for $35 \mathrm{~mm}$ and $20 \mathrm{~mm}$ diameter diameters. The mentioned diameters are the initial conditions in designing the shape and size of the jaws. From a design point of view, the EMCO Concept Turn 105 is capable of machining a maximum diameter of $75 \mathrm{~mm}$ and a maximum length of $121 \mathrm{~mm}$. Designed parts do not exceed the boundary dimensions given by the lathe construction, which means that they can be manufactured.
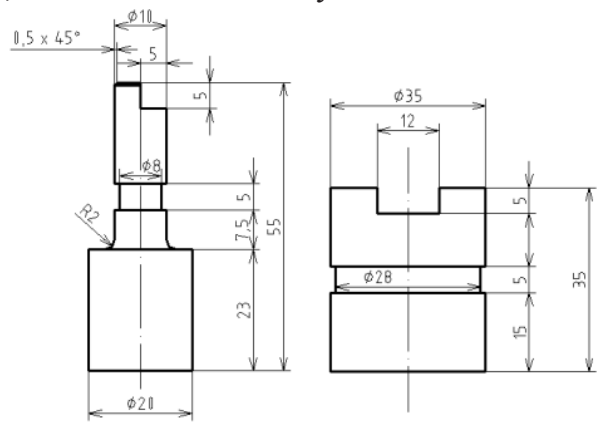

Fig. 3. New part base 


\subsection{Material of components manufactured on the lathe}

The material from which the components will be produced affects the design of the jaw material. It is necessary for the jaws to be of material that will not deform after the work piece is clamped by clamping forces and cutting forces. New parts will be made of aluminum. Since it is a relatively soft kind of material, in terms of its workability, the demands on the jaw material are not high.

\subsection{Material of exchangeable jaws}

The RÖHM, the manufacturer of the chuck situated on the EMCO Concept Turn 105, presents in its catalogs the examples of jaws suitable for the chuck. All jaws are made of material $16 \mathrm{MnCrS5}$. Based on this fact, new jaws will be chosen also from the same material. Thus, the jaw material will be the structural steel designated $16 \mathrm{MnCrS5}$.

The characteristics of the 16MnCrS5 structural steel for carburizing according to EN10084 are as follows: Low-alloy stainless steel manganese-chromium steel for cementation [2].

\subsection{Shape, dimensions and properties of pneumatic chuck}

The shape and dimensions of the pneumatic chuck (Figs. 4 and 5) to which the jaws are clamped are another starting condition for the shape and dimension of the newly designed jaws. The dimensions shown in Fig. 4 and 5 are from the catalog provided by the RÖHM chuck manufacturer. The given dimensions must also be kept on the clamping surface of the newly designed jaws so that the jaws fit accurately on the chuck when clamped. The clamping of the jaws on the lathe chuck is ensured by means of a threaded bolt M8x20, DIN 9128.8 with a cylindrical head.

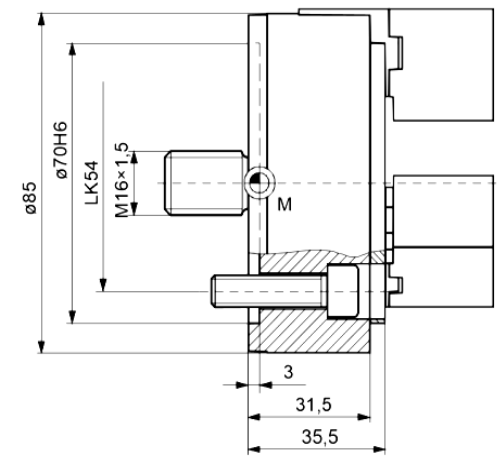

Fig. 4. The dimensions of pneumatic chuck [1]

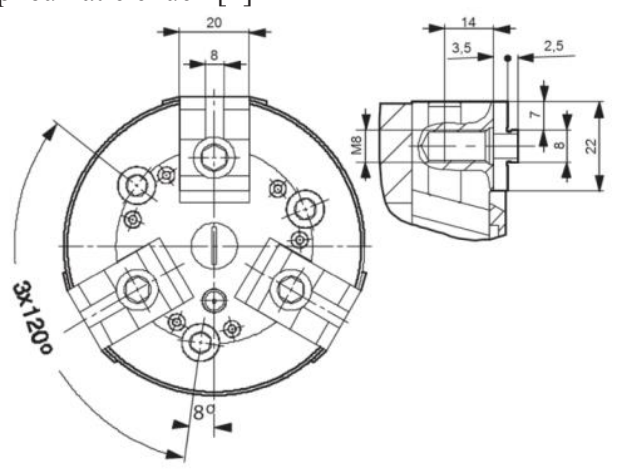

Fig. 5. The dimensions of part 3 - pneumatic chuck with jaws marked KFD85/3 to which jaws are clamped [1] 
The shape of the designed jaws must provide basic alignment and clamping functions. The jaws must be manufactured with sufficient precision, as they need to be evenly balanced at high spindle speeds (max. $4500 \mathrm{rpm}$ ) and also need to be as small as possible.

Another factor affecting the design of the jaws is the clamping force and clamping pressure. The clamping force is controlled by adjusting the pressure with a pneumatic valve. The minimum clamping pressure is $0,2 \mathrm{MPa}$ and the maximum is $0,6 \mathrm{MPa}$. The clamping pressure for aluminum is recommended from 0,3 to $0,4 \mathrm{MPa}$. The clamping force of the chuck also affects the stiffness of the jaws. The stiffness of the jaws shall be such as to be able to withstand external loads.

The clamping force must be calculated for the workpiece clamped in the triple chuck. The clamping force $F_{u}$ is determined from the condition of the equilibrium moments of the frictional forces $M t$ between the jaws and the blank and the moment of the main cutting force component $M c$ :

$$
M_{t} \geq M_{c}
$$

after substitution

$$
i \cdot F_{t} \cdot \frac{D}{2} \geq F_{c} \cdot \frac{D}{2}
$$

Where:

$i$ - number of jaws [pc]

$F_{t}-$ friction between jaws and blank [N]

$D$ - diameter of blank [mm]

$F_{c}$ - force of the main component of the cutting force [N]

Forces acting on a workpiece clamped in a 3 -jaw chuck are schematically depicted in Fig.6.

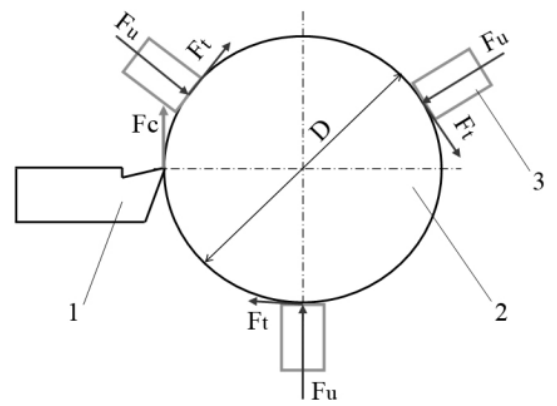

Fig. 6. Force acting on workpiece clamped in 3-jaw chuck

1- cutting tool, 2- workpiece, 3- jaw [5]

From the physical condition for shear friction:

$$
F_{t}=F_{u} \cdot f_{t}
$$

Where:

$f_{t}$ - coefficient of friction [-]

When calculating the clamping force, the surface roughness of the clamped surface, the surface of the jaws and the contamination of the surface with the coolant (if used) must be taken into account. The clamping safety factor $\mathrm{K}=1,5$ is chosen for normal operation. After fitting and adjusting, the clamping force size $F_{u}[\mathrm{~N}]$ is calculated:

$$
F_{u} \geq \frac{K \cdot F_{c}}{i \cdot f_{t}}
$$

Main component of cutting force $F_{c}[\mathrm{~N}]$ is calculated: 


$$
F_{c}=k_{s} \cdot b \cdot h
$$

Where:

$k_{s}$ - cutting resistance for given material [N.mm $\left.{ }^{-2}\right]$

$b$ - chip width [mm]

$h$ - chip thickness [mm]

There are given boundary conditions for turning, on the basis of which the required clamping force is calculated for aluminum blanks:

Cutting depth: $a_{p}=3 \mathrm{~mm}$

Feed rate: $f=0,5 \mathrm{~mm}$

Main cutting edge adjustment angle: $\kappa_{r}=60^{\circ}$

Jaws: $i=3$

Cutting resistance for aluminum: $p c s=900 \mathrm{~N} \cdot \mathrm{mm}^{-2}$

Coefficient of friction (steel-aluminum): $f_{t}=0,30$

The maximum clamping force of the 3-jaw pneumatic chuck specified by the manufacturer RÖHM is $12,000 \mathrm{~N}$, the maximum clamping force of the chuck on the given $\mathrm{CNC}$ lathe is $3000 \mathrm{~N}$ and the calculated clamping force is $2250 \mathrm{~N}$, indicating that the clamping is satisfactory.

\section{Design of new exchangable jaws}

The jaw construction must take into account the manufacturing and technological capabilities of the iCIM-3000 production system. As the jaws are part of the EMCO Concept Turn 105 lathe system, they must improve their work quality and not reduce it.
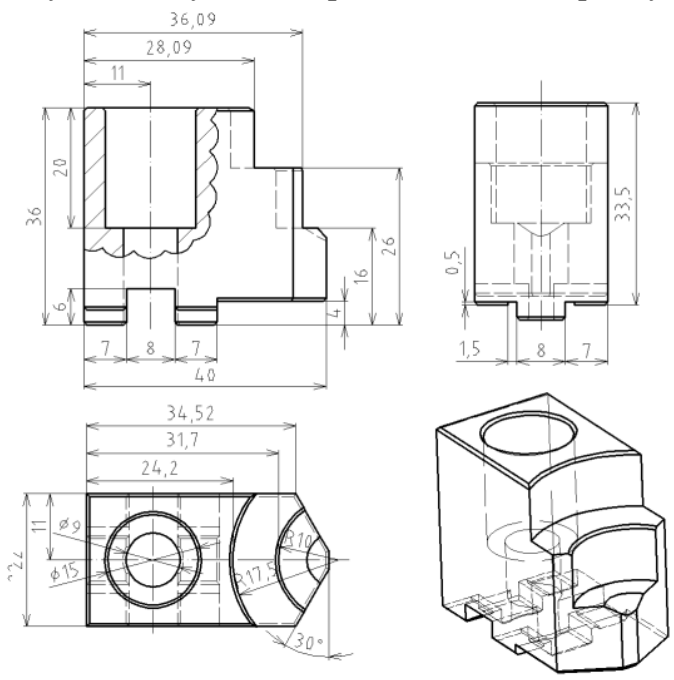

Fig. 7. Design of exchangable jaws [5]

Accordingly, the following general requirements for the design of the jaws can be formulated:

- The technical characteristics of the jaws must comply with the technological system (clamping on the chuck, accuracy and stiffness of the jaws, stability of properties, lifetime of the jaws),

- From a conceptual point of view, they must provide, together with the chuck, with which they form a single element the essential functions of the preparation, 
- From a structural point of view, they must have a suitable arrangement and design of the clamping surfaces to ensure that the clamping force components act against the fixed stops,

- They must ensure sufficient production, quality and economy of production,

- They must provide suitable performance characteristics, for example to allow chip removal and cleaning, be balanced and have the least weight possible,

- From the point of view of the wear on the functional surfaces of the fixture, the surfaces subject to wear must be hard (hardened or cemented and hardened) with respect to the materials being machined, replaceable at the required accuracy.

Stepped jaws are proposed, the basic dimensions of which are shown in Fig. 7. These jaws are able to clamp parts with diameters of 20 and $35 \mathrm{~mm}$ due to their shape. They require only minimal maintenance, as parts without cooling will be machined. The clamping surfaces of the interchangeable jaws themselves will be cleaned from chipps with compressed air [3-6].

\section{Summary}

New exchangeable jaws were designed based on a detailed analysis of the design conditions. The original jaws were shaped to fit only one diameter of the blanks. The chuck on a given $\mathrm{CNC}$ lathe has a very small clamping range to clamp two diameters from a new set of parts. It was not possible to buy new jaws because the jaws offered on the Slovak market do not allow us to clamp the required combinations of dimensions.

The design itself was influenced by individual conditions such as the shape and dimensions of parts, the material of the components, the shape and dimensions of the current pneumatic chuck located on the $\mathrm{CNC}$ lathe. All the conditions mentioned, as well as the stiffness, accuracy and durability of the jaws, the stability of the jaws, the maintenance of the jaws and others, were taken into account when designing the new jaws. Thus, the individual conditions had determined the shape of the newly designed jaws while ensuring a sufficiently accurate clamping and thus accuracy of production.

Acknowledgement: This paper was written thanks to the project KEGA 021STU-4/2018 with name "Development of a laboratory for the design and maintenance of production systems supported by the use of Virtual Reality".

\section{References}

1. Emco Concept Turn 105 PC-ř́izený CNC soustruh pro výuku, Itax Precision spol. s r.o., Praha, (2003)

2. Přehled vlastností oceli $16 \mathrm{MnCr} 5$, Bolzano, (2014) In:

http://prirucka.bolzano.cz/cz/technickapodpora/techprirI/tycovaocel/ocelikcementovani /16MnCr5/

3. J. Oravcova, P. Koštál, D. R. Delgado Sobrino, R. Holubek, Clamping Fixture Design Methodology for the Proper Workpiece Insertion, Appl. Mech. Mater., vol. 309, 20-26, (2013)

4. P. Košţál, A. Mudriková, P. Kerak, Clamping fixture for new paradigms of manufacturing, DAAAM, vol. 21, no. 1, 0361-0362, (2010)

5. J. Oravcova, The Numerical Simulation of Workpiece Clamping, Appl. Mech. Mater., vol. 474, 218-223, (2014)

6. M. Pressel, Design of interchangeable jaws for pneumatic lathe chuck on CNC lathe EMCO Concept Turn 105, Diploma thesis, MTF STU Trnava (2014) 